\title{
Investigating the Key Success Factors of Social Marketing in Promoting Environmental Consciousness: A Dematel-Based Approach
}

\author{
Chi-Horng Liao ${ }^{1}$ \\ ${ }^{1}$ Department of Communication Studies, Tzu Chi University, Hualien, Taiwan \\ Correspondence: Chi-Horng Liao, Department of Communication Studies, Tzu Chi University, Hualien, Taiwan. \\ E-mail: lchjerry@mail.tcu.edu.tw
}

Received: February 5, 2020 Accepted: March 9, 2020 Online Published: March 12, 2020

doi:10.5539/ijms.v12n2p1 URL: https://doi.org/10.5539/ijms.v12n2p1

\begin{abstract}
Due to the overuse of the environment and natural resources, our environment has suffered long-term damage and natural disasters have been exacerbated by climate change, resulting in a significant impact on people's livelihood and security. People must consider saving the environment as everyone's responsibility. Hence, Environmental consciousness should be promoted to inspire public participation. This study used the Decision Making Trial and Evaluation Laboratory (DEMATEL) method to identify the key success factors of social marketing in promoting environmental consciousness. The DEMATEL method has been proven highly effective in gathering the views of experts and thereby providing information of greater reliability in many areas. The results of this research suggest that "Take advantage of existing successful campaign", "Using appropriate media channel to increase the participation", and "Enhancing campaign success by appropriate research" are the main strategies for promoting environmental consciousness. The findings of this study may be used in future success factor evaluations where social marketing is compared with other measures aiming to increase the efficiency of the campaign.
\end{abstract}

Keywords: social marketing, environmental consciousness, key success factors, Decision Making Trial and Evaluation Laboratory (DEMATEL)

\section{Introduction}

There are various signs indicating that the Earth's natural environment is changing toward unfavorable direction for species, which is highly suspected to be connected with human economic activities (Lin \& Lv, 2014). The activities not only consume huge amounts of natural resources, but also lead to the disposal of tons of pollutants into the environment at levels which nature can no longer absorb. This situation generates problems such as climate change, global warming, pollution, waste production, loss of biodiversity, and many more (Chakraborty et al., 2000). Environmental protection is a practice of protecting the natural environment on government, organization or individual levels, for the benefit of both the environmental media and humanity (Apichatibutarapong, 2018). Environmental conservation and protection from pollution has become a central and important issue at the international level. Therefore, environmental consciousness has been a necessity of life, and it must be developed for all, to adopt the future of countries and civilizations.

Environmental consciousness is the individual's understanding of the requirements of the environment and the development of his correct behaviors towards the environment. This concept is convincing human on the knowledge by theorizing emotion engendering that can be participator in environmentally friendly, concerns and responsibilities with environmental impact (Krukaseta \& Sahachaisaereeb, 2010). There were many researchers work on increasing environmentally conscious behavior in individuals, business and society (Sanchez, 2010; Hiramatsu et al., 2016; Sena at al., 2017; Moultrie et al., 2016). Several researchers also applied the social marketing strategy to spread the concept in relate to environmental consciousness (Eagle et al., 2017; Chen et al., 2015; Gordon et al., 2018; Perez-Mujica et al., 2014; Low et al., 2013; Evans et al., 2014). Social marketing is the systematic application to achieve specific behavioral goals relevant to the social goal (Corner \& Randall, 2011). Hence, the social marketing efforts have created high levels of environmental consciousness including behavior change. The main objectives of this research are to identify the social marketing key success factor that most influence the target audience in relates with environmental consciousness.

This study is organized as follow: The first section introduces the purpose of the research and the background. In 
the following section, the author reviews the materials and methods of this study such as definition and application of social marketing, the key success factor of social marketing, the importance of environmental consciousness and social marketing in relate with environmental consciousness. The Decision Making Trial and Evaluation Laboratory (DEMATEL) method applied in this study will also be present in section 3. The fourth section is the results and discussion. This research ends with the conclusions and recommendations which include the study implication and future research suggestions.

\section{Literature Review}

This section discusses the review of literature for social marketing, environmental consciousness, the key success factors of social marketing and the research participants.

\subsection{Social Marketing}

"Social Marketing is the application of commercial marketing technology to the analysis, planning and execution of programs designed to influence the behavioral change of target audiences in order to improve the personal and social welfare" (Andreasen, 2002). Furthermore, Kotler et al. (2002) defined social marketing as a "means to influence the targeted audience to voluntarily accept, refuse, correct, or give up certain behaviors by applying the principles of marketing and to further promote the benefits of individuals, organization, or society". It is worth noticing that voluntary behavioral changes are the key products offered by practitioner. Many commercial companies, non-profit organizations, governments, and agencies, applied social marketing as the tools to communicate in order to influence and affect the individual by spread the concept through meaningful messages (Low et al., 2013).

Social Marketing principles and techniques can be used to benefit society in general and the target audience. This can be done by the integration of research, evidence-based practice, and the use of social-behavioral theory jointly with the perceptions from individuals, practitioner and society (Lefebvre, 2012). The practitioner may apply these perspectives to design more effective and efficient strategy to enhance the success of social marketing campaign. Recent research has identified that behavior change is influential when more key success factors of social marketing are used (Saunders et al., 2014; Kubacki et al., 2015). Key success factors of social marketing have been established in a variety of contexts including healthy eating (Pettigrew, 2014), alcoholism (Dietrich et al., 2015), reducing mental health humiliation (Sampogna et al., 2017), addressing vaccine hesitancy (Nowak et al., 2015), and fall prevention (DiGuiseppi et al., 2014) in an effort to support the research on social marketing to understand the application of each key success factors. This research extends on reviews the success factors of social marketing in various application.

\subsection{Social Marketing Key Success Factors}

Every social marketing campaign needs to be evaluated carefully in order to fit the specific situation and to a specific targeted audience. Thus, this research proposed a social marketing framework that involves twelve main key success factors which were concluded by Kotler and Lee (2009). These 12 factors are:

(C1) Take advantage of existing successful campaign-The benefits of social marketing can be learned from the successes and failures of others. The used of success experience in planning social marketing strategies can increase effectiveness and efficiency (Key \& Czaplewski, 2017).

(C2) Start with most ready target audience intervention-Social marketing campaigns would be increased the chances of success by starting with the people most ready for action. These means that the people has the want or need to the proposed behavior; has the knowledge or information regarding the benefits of the behavior; or has the belief that they can perform the behavior. The increasing accessibility of common tools and experienced consultants can reassure the implementers that it is easy to make social marketing work (Andreasen, 2002).

(C3) Creating simple and determine slogan for an achievable behavior-A simple, clear, action-oriented message is positively to encourage the target audience to adopt, reject, modify, or abandon a specific behavior. The findings of Mitchell et al. (2017) support that a strong slogan can facilitate both initial behavior change and the maintenance of such behavior change. Nevertheless, the slogan must be widely spread and advertised.

(C4) Promote tangible goods or services to assist the behavioral change-Introduce commercial entities or services to help the target audience to perform the behavior. Evans et al. (2014) indicated that the campaigns have used both individual modification and infrastructure improvement schemes to create an environment in which behavior change can occur. Base from the study of Buyucek et al. (2016), serving water with alcohol can reduce excessive drinking.

(C5) Emphasize costs and benefits of behavioral change-It is suggested that to highlight the benefits of change 
attractive enough, and the costs of change low enough, in order to encourage the better behavior. Pettigrew (2011) concluded that any social marketing campaign that aims to influence dietary needs to take into account relative cost of competing products. It is more effective when the information about the key benefits is communicated in a meaningful way (Nowak, 2015).

(C6) Make access easy-Successful campaign provides target market easy to access, convenient locations to acquire tangible objects and received services. Mitchell et al. (2017) proposed that simplifying the process may be the tool for encouraging behavior change.

(C7) Developing an attractive message to reinforce the behavioral change-Applying appropriate massages to influence or encourage public behaviors. Kataria and Larsen (2009) indicated that an effective and clear message as the influencing instrument of battery collection campaign. Forbus and Snyder (2013) emphasized that social marketer should consider developing messages that encourage target audience to give and receive both support and comfort. Wymer (2010) also concluded that social marketer must spread attractive message to influence individuals to adopt healthy behavior.

(C8) Using appropriate media channel to increase the participation-Successful campaigns used appropriate media that effectively reach target audience with appealing sponsors, spokespersons and/or formats. Chen et al. (2015) emphasized that public participation can be used instead of traditional communication channels. Reichert et al. (2001) found that advertisement using attractive object were more effective in attaining target audience's attention. DiGuiseppi et al. (2014) highlighted that the benefits of Church-based channel that communicated marketing message through church leaders, trained messages and printed material to prevent older adults fall. The dimensions of mass media could be used into social marketing campaigns in order to achieve voluntary behavior change (Esch et al., 2013).

(C9) Providing the feedback system to the audience-The feedback system gains the commitments of the target audience to perform the intended behavior. Volunteers acted as the significant role in the successful implementation of the campaign, and convenient response mechanisms have played an important role in volunteer recruitment (Boehm, 2009).

(C10) Maximize the promotion of the information-An ideal campaign is to make sure that the target audience received the message send. The social marketing should ensure that the target audience received and understands the message (Merritt et al., 2017).

(C11) Enhancing campaign success by appropriate research-To make the campaign more efficient, the social marketer needs to do appropriate research to answer the problems that might be encounter during the campaign. Perez-Mujica et al. (2014) did further research to design and stimulate the behavioral social marketing campaign. Solaiman et al. (2015) also concluded that success of social marketing dependent on customer research.

(C12) Track the results and make adjustment-Successful campaigns provide ways to monitor progress and adjustments in order to planned strategies that support the objectives of the campaign. Aras (2011) suggests that the social marketer must evaluate and monitor the campaign by using baseline data, then data from several points in time after the initial campaign launch.

The most credible and reliable factors of success for the social marketing efforts is the extent to which the campaign objectives and goals are met. These 12 factors that can contribute to achieving directed result were proposed in this study.

\subsection{Environmental Consciousness}

Environmental consciousness can be broadly understood as people's perception of their relation to nature. Sánchez and Lafuente (2010) define environmental consciousness as a multidimensional behavior-oriented concept can be considered to be equivalent to the attitudinal dimension of pro-environmental behavior. It is the attitude concerning environmental outcomes of human behavior. Starting from the typical definition of attitude, environmental consciousness is a tendency to react to environmental concerns in a certain manner (Ham et al., 2015). It is an aspect of one's individual system of beliefs and values on a part of social conscious.

Environmental issues have an increasing popularity among researchers. Recent research evaluated and investigated environmental consciousness in different circumstance. Moultrie et al. (2015) employed environmentally-conscious as the tool to design of medical device. Deniz (2016) concluded the importance of environmental consciousness education as crucial factor to acquire knowledge through the view point of sustainability. Iosifidi (2016) determined that environmental consciousness has a significant effect on green labor supply. Umuhire and Fang (2016) proved that enhancing public ocean environmental consciousness will lead to increased public support for ocean environmental protection. Kotchen and Moore (2007) indicates that 
environmental consciousness essentially affects the choice of green power for domestic use. Therefore, promoting environmental consciousness is the way to enhance an environmental steward and participate in creating a feasible living surrounding for the humanity.

\subsection{Social Marketing in Relate with Environmental Consciousness}

Social marketing is one of the approaches for promoting environmental consciousness to the public. In early research, Maibach (1993) explored that mass media can be used in communication campaigns that seek to develop solutions to environmental problems. McDaniel and Rylander (1993) also supported that social marketing is one of the business strategies, and that the increasing environmental consciousness makes it incumbent on consumer marketer to lead the way in environmental programs. Barr and Prillwitz (2014) recommended social-marketing approach of increasing individuals' environmental consciousness to promote greener consumption. Eagle et al. (2016) analyzed the role of social marketing in prompting behavioral change and encouraging a transition to renewable energy. Dollatabady et al. (2012) also suggested that the integration of social marketing principles in community programs aimed at dealing with environmental issue. Thus, Social marketing is an adaptable approach, increasingly being used to achieve and sustain behavior relevant to a range of social issues such as environmental consciousness. This research proposes social marketing as important strategy in promoting environmental consciousness to the target audience.

\subsection{Research Participant}

Tzu Chi Foundation Taiwan was established in 1966. The mission of the foundation beginning with Charity and extended into Medicare, Education, and Humanistic Culture. The foundation later added the efforts in Bone Marrow Donation, Environmental Protection, Community Volunteerism, and International Relief. In the case of Environmental Protection, the Tzu Chi volunteers was inspired by the founder that environment protection is a way to care for the earth and a way to cultivate the mind. In practicing recycling, the volunteers serve as gardeners of the earth. Therefore, the foundation promotes this environmental consciousness to the public and hoping to influence more people to join this earth loving practices and behaviors.

This research selected several Tzu Chi volunteers whom were recommended by the board of the management with at least 10 years' experience in practicing recycling activities to answer the survey. With their expertise in promoting environmental consciousness to the society, the researcher expects to gather their opinions in order to identify the influential key success factors of social marketing that promotes environmental consciousness. The evaluation process will be presented in following section.

\section{Research Method}

DEMATEL approach was developed by Science and Human Affairs program of the Battle Memorial Institute of Geneva from 1972 to 1976. This approach is a comprehensive method for analyzing and designing structural models of causal relationships between complex factors (Wu \& Lee, 2007). DEMATEL method shows the relationships among factors and prioritizing the criteria based on the type of relationships and severity of the effects on each other (Gandhi et al., 2015). This method assists in capturing the contextual relations between elements in the system and defines the strength of the interrelationship ( $\mathrm{Wu}, 2008)$. DEMATEL helps to analyze the factors by classifying them into cause and effect group and illustrates the interrelationship between them through causal relationship diagram. This scientific approach could improve understanding of the complex structure of the specific problem and contribute to identification of relationships between factors, workable solutions by a structural model (Tzeng et al., 2007). The significance of DEMATEL is to assist decision makers of organization to distinguish the relationships among key factors and to clarify the essential elements of an existing problem (Zhou et al., 2011; Zhou et al., 2017).

Scientists and Researchers applied DEMATEL approach in the field of marketing and environment protection. In the case of marketing, Altuntas and Yilma (2016) used DEMATEL method to evaluate the dimensions of marketing resources. Gholamil et al. (2015) developed risk management marketing strategy using DEMATEL techniques. Kumar and Dash (2016) constructed influential network relation map of consumer decision-making in e-marketplace applied DEMATEL method. In relate with environment protection, Goyal et al. (2019) analyzed environment sustainability enablers using fuzzy DEMATEL. Tsai et al. (2015) used the Fuzzy DEMATEL to Determine Environmental Performance. Kaur et al. (2018) investigates barriers in green supply chain management based DEMATEL approach. Ershadi and Ashtiyani (2019) examined the factors affecting environmental risks using a hybrid approach of DEMATEL. In this research, the social marketers need to construct the best strategy in order to promote the behavioral change to the target audience. Thus, DEMATEL is the suitable method to construct the causal network structure among all factors of social marketing to promote environmental consciousness. 
The flow diagram of formulating DEMATEL is presented in Figure 1. And, the procedure of DEMATEL would be summarized in the following steps based on Horng et al. (2013) and Muhammad and Cavus (2017):

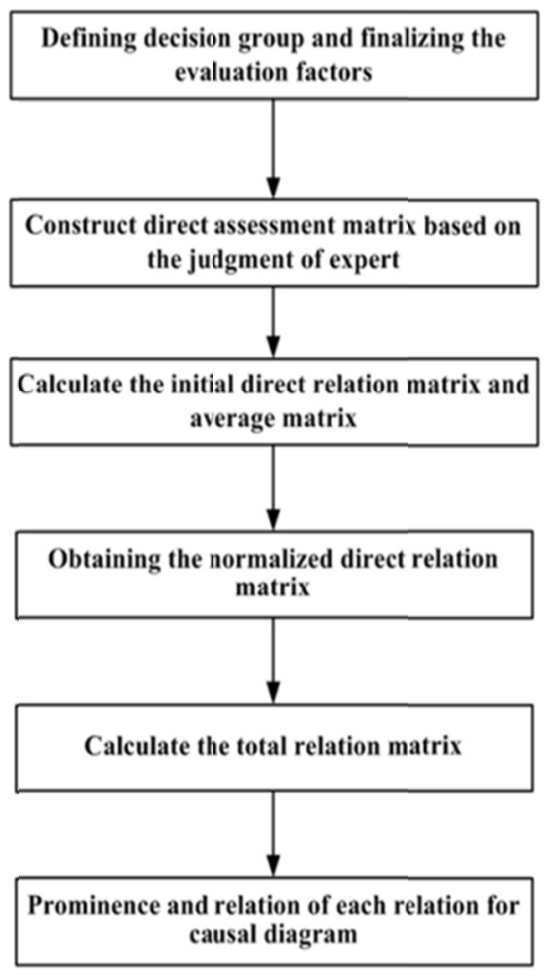

Figure 1. The flow diagram of formulating DEMATE

Step 1: Define decision group and evaluation factors. Critical literature review is required in this initial step to explore and gather relevant information and data. The decision group is necessary to form for discussion on the issue to archive the objective. The probable key success factors associated with social marketing are selected and finalized based on the information gathered and expert opinion.

Step 2: Calculate the original average matrix $A$. Each expert was asked to evaluate the direct influence of any two factors according to their experience. The scale of integers ranged from 0 to 3 ["No influence (0)", "Low influence (1)", "Medium influence (2)", and "High influence (3)"]. The experts selected the higher score when they believed that the factor of attribute $i$ exerted a stronger possibility of direct influence on the inability of attribute $j$. Each respondent would produce a direct matrix. The matrices of $E^{1}, E^{2}, E^{3} \ldots E^{p}$ is the measure score from $\mathrm{p}$ experts. Let the $(i, j)$ element of matrix $E$ is denoted by $\mathrm{e}_{i j}$, and $\mathrm{e}_{i j}$ represents the pair of degree of effect on $i$ factor effects $j$ factor. The average matrix $A$ can be constructed as

$$
A=\left[a_{i j}\right]_{n \times n}=\frac{1}{p} \sum_{k=1}^{p} e_{i j}^{k}
$$

Where $e_{i j}^{k}$ represent each expert's evaluation and $p$ is the number of experts.

Step 3: Calculate the initial directly affected matrix $Z$ (i.e., $Z=\left[\mathrm{z}_{i j}\right]_{\mathrm{n} \times \mathrm{n}}$ ). The matrix $Z=\left[z_{i j}\right]_{n \times n}=\left[a_{i j} / s\right]_{n \times n}$, which $Z$ can be obtained by normalizing average matrix A and $s$ can be represented as $s=\max _{(}\left(\max _{j} \sum_{i=1}^{n} C_{i j}\right.$, $\max _{i} \sum_{j=1}^{n} C_{i j}$ ). Each element in matrix $Z$ falls between zero and one, and all principal diagonal factors are equal to zero.

Step 4: Calculate the total relation matrix $\mathrm{T}$ (i.e., $\mathrm{T}=\left[\mathrm{t}_{i j}\right]_{\mathrm{n} \times \mathrm{n}}$ ). When $\lim _{k \rightarrow \infty} Z^{k}=[0]_{n \times n}$. The $T$ is represented as $T=\sum_{k=1}^{\infty} Z^{k}=Z(I-Z)^{-1}$, where $I$ is the identity matrix The row sum of the $i$ th row of matrix $T$ is calculated as $\mathrm{D}=\left[d_{i}\right]_{n \times 1}=\left[\sum_{j=1}^{n} t_{i j}\right]_{n \times 1}$, which summarize the direct and indirect impact of factor $i$ on the other factor. Similarly, $r_{j}$ denotes the column sum of the $j$ th column of matrix $T$ and can be represented as

$$
R=\left(\left[r_{j}\right]_{1 \times n}\right)^{T}=\left(\left[\sum_{i=1}^{n} t_{i j}\right]_{1 \times n}\right)^{T}
$$


This shows the direct and indirect effect the factor $j$ has received from the other factor based on experts' perspectives. In addition, when $i=j$ (i.e., the sum of the row and column aggregates), $d_{i}+r_{i}$ refers to "prominence", which shows the total effects of factor $i$ and indicates the level of importance for the whole evaluation system. On the contrary, the difference of $d_{i}-r_{i}$ refers to "relation", which represents the net effect between a pair of factors; if the value is positive, this means the factor is a net cause. The factors are net receivers or result when the values of $d_{i}-r_{i}$ are negative.

Step 5: The causal diagram is paired as $\left(d_{i}+r_{i}, d_{i}-r_{i}\right)$ with the horizontal axis as $\mathrm{D}+\mathrm{R}$ and the vertical axis as $\mathrm{D}-\mathrm{R}$ which providing valuable insight for making decisions. The network-relationship map helps social marketer to decide which factor is most important and to identify the cause and effect factors.

\section{Results and Discussion}

This study applied the DEMATEL method to construct a cause and effect model for the 12 key success factors of social marketing. The proposed model steps are as follow:

Step 1: Calculate the original average matrix A

After calculating the aggregation value of subjective judgement from the opinion of 10 experts of the influence from $\mathrm{C} 1$ on $\mathrm{C} 2$ equals to $2.5, \mathrm{C} 1$ on $\mathrm{C} 3$ equals to 2.2 and so on. The result presents in Table 1 .

Table 1. The DEMATEL initial direct relations matrix

\begin{tabular}{lllllllllllll}
\hline initial A & $\mathrm{C}_{1}$ & $\mathrm{C}_{2}$ & $\mathrm{C}_{3}$ & $\mathrm{C}_{4}$ & $\mathrm{C}_{5}$ & $\mathrm{C}_{6}$ & $\mathrm{C}_{7}$ & $\mathrm{C}_{8}$ & $\mathrm{C}_{9}$ & $\mathrm{C}_{10}$ & $\mathrm{C}_{11}$ & $\mathrm{C}_{12}$ \\
\hline $\mathrm{C}_{1}$ & 0.0000 & 2.5000 & 2.2000 & 2.0000 & 2.4000 & 2.4000 & 2.3000 & 2.2000 & 2.3000 & 2.4000 & 2.3000 & 2.1000 \\
$\mathrm{C}_{2}$ & 1.7000 & 0.0000 & 1.7000 & 1.7000 & 2.4000 & 1.9000 & 1.8000 & 2.0000 & 1.9000 & 1.9000 & 1.4000 & 2.2000 \\
$\mathrm{C}_{3}$ & 1.2000 & 1.7000 & 0.0000 & 1.0000 & 1.3000 & 2.1000 & 2.2000 & 1.1000 & 1.6000 & 1.2000 & 1.3000 & 1.3000 \\
$\mathrm{C}_{4}$ & 1.3000 & 1.6000 & 1.0000 & 0.0000 & 2.3000 & 1.9000 & 1.2000 & 1.3000 & 1.4000 & 1.0000 & 1.3000 & 1.4000 \\
$\mathrm{C}_{5}$ & 1.5000 & 1.2000 & 1.3000 & 1.2000 & 0.0000 & 1.7000 & 1.3000 & 1.3000 & 1.3000 & 1.1000 & 1.1000 & 1.4000 \\
$\mathrm{C}_{6}$ & 2.2000 & 2.4000 & 2.2000 & 2.3000 & 2.0000 & 0.0000 & 2.1000 & 2.2000 & 1.5000 & 1.3000 & 1.3000 & 1.4000 \\
$\mathrm{C}_{7}$ & 1.5000 & 1.9000 & 2.1000 & 1.7000 & 1.5000 & 1.7000 & 0.0000 & 1.3000 & 2.0000 & 1.6000 & 1.5000 & 0.9000 \\
$\mathrm{C}_{8}$ & 2.0000 & 2.2000 & 1.9000 & 2.3000 & 2.2000 & 2.2000 & 2.0000 & 0.0000 & 1.5000 & 1.9000 & 2.0000 & 1.7000 \\
$\mathrm{C}_{9}$ & 2.0000 & 1.9000 & 1.7000 & 1.8000 & 2.0000 & 1.4000 & 1.2000 & 1.3000 & 0.0000 & 1.1000 & 1.1000 & 1.9000 \\
$\mathrm{C}_{10}$ & 1.7000 & 1.9000 & 2.2000 & 2.0000 & 2.2000 & 1.9000 & 2.2000 & 2.0000 & 1.3000 & 0.0000 & 1.1000 & 1.2000 \\
$\mathrm{C}_{11}$ & 2.0000 & 2.2000 & 2.3000 & 2.3000 & 2.1000 & 2.3000 & 2.3000 & 2.2000 & 2.5000 & 2.3000 & 0.0000 & 2.3000 \\
$\mathrm{C}_{12}$ & 1.5000 & 2.1000 & 2.1000 & 1.7000 & 2.2000 & 2.0000 & 2.0000 & 2.0000 & 1.6000 & 1.5000 & 1.7000 & 0.0000 \\
\hline
\end{tabular}

Step 2: Calculate the initial directly affected matrix Z (Normalization)

The sum of each intersection value is divided for the maximum value of the sum of rows and the sum of columns from initial direct relation matrix. The maximum value after calculation is 25.1 . The normalization direct relation matrix is explicit in following Table 2.

Table 2 . The initial directly affected matrix $\mathrm{Z}$

\begin{tabular}{lllllllllllll}
\hline $\mathrm{Z}$ & $\mathrm{C}_{1}$ & $\mathrm{C}_{2}$ & $\mathrm{C}_{3}$ & $\mathrm{C}_{4}$ & $\mathrm{C}_{5}$ & $\mathrm{C}_{6}$ & $\mathrm{C}_{7}$ & $\mathrm{C}_{8}$ & $\mathrm{C}_{9}$ & $\mathrm{C}_{10}$ & $\mathrm{C}_{11}$ & $\mathrm{C}_{12}$ \\
\hline $\mathrm{C}_{1}$ & 0.0000 & 0.0996 & 0.0876 & 0.0797 & 0.0956 & 0.0956 & 0.0916 & 0.0876 & 0.0916 & 0.0956 & 0.0916 & 0.0837 \\
$\mathrm{C}_{2}$ & 0.0677 & 0.0000 & 0.0677 & 0.0677 & 0.0956 & 0.0757 & 0.0717 & 0.0797 & 0.0757 & 0.0757 & 0.0558 & 0.0876 \\
$\mathrm{C}_{3}$ & 0.0478 & 0.0677 & 0.0000 & 0.0398 & 0.0518 & 0.0837 & 0.0876 & 0.0438 & 0.0637 & 0.0478 & 0.0518 & 0.0518 \\
$\mathrm{C}_{4}$ & 0.0518 & 0.0637 & 0.0398 & 0.0000 & 0.0916 & 0.0757 & 0.0478 & 0.0518 & 0.0558 & 0.0398 & 0.0518 & 0.0558 \\
$\mathrm{C}_{5}$ & 0.0598 & 0.0478 & 0.0518 & 0.0478 & 0.0000 & 0.0677 & 0.0518 & 0.0518 & 0.0518 & 0.0438 & 0.0438 & 0.0558 \\
$\mathrm{C}_{6}$ & 0.0876 & 0.0956 & 0.0876 & 0.0916 & 0.0797 & 0.0000 & 0.0837 & 0.0876 & 0.0598 & 0.0518 & 0.0518 & 0.0558 \\
$\mathrm{C}_{7}$ & 0.0598 & 0.0757 & 0.0837 & 0.0677 & 0.0598 & 0.0677 & 0.0000 & 0.0518 & 0.0797 & 0.0637 & 0.0598 & 0.0359 \\
$\mathrm{C}_{8}$ & 0.0797 & 0.0876 & 0.0757 & 0.0916 & 0.0876 & 0.0876 & 0.0797 & 0.0000 & 0.0598 & 0.0757 & 0.0797 & 0.0677 \\
$\mathrm{C}_{9}$ & 0.0797 & 0.0757 & 0.0677 & 0.0717 & 0.0797 & 0.0558 & 0.0478 & 0.0518 & 0.0000 & 0.0438 & 0.0438 & 0.0757 \\
$\mathrm{C}_{10}$ & 0.0677 & 0.0757 & 0.0876 & 0.0797 & 0.0876 & 0.0757 & 0.0876 & 0.0797 & 0.0518 & 0.0000 & 0.0438 & 0.0478 \\
$\mathrm{C}_{11}$ & 0.0797 & 0.0876 & 0.0916 & 0.0916 & 0.0837 & 0.0916 & 0.0916 & 0.0876 & 0.0996 & 0.0916 & 0.0000 & 0.0916 \\
$\mathrm{C}_{12}$ & 0.0598 & 0.0837 & 0.0837 & 0.0677 & 0.0876 & 0.0797 & 0.0797 & 0.0797 & 0.0637 & 0.0598 & 0.0677 & 0.0000 \\
\hline & & & & & & & & & & & &
\end{tabular}

Step 3: Calculate the total relation matrix $\mathrm{T}$

The limit of $Z^{\wedge} \mathrm{k}$ is $\llbracket[0] \rrbracket \_(12 \times 12)$ as $\mathrm{k}$ approaches infinity. Total relation matrix is acquired from the 
generalized direct relation matrix. The matrix is shown in Table 3.

Table 3 . The total relation matrix

\begin{tabular}{lllllllllllll}
\hline $\mathrm{T}$ & $\mathrm{C}_{1}$ & $\mathrm{C}_{2}$ & $\mathrm{C}_{3}$ & $\mathrm{C}_{4}$ & $\mathrm{C}_{5}$ & $\mathrm{C}_{6}$ & $\mathrm{C}_{7}$ & $\mathrm{C}_{8}$ & $\mathrm{C}_{9}$ & $\mathrm{C}_{10}$ & $\mathrm{C}_{11}$ & $\mathrm{C}_{12}$ \\
\hline $\mathrm{C}_{1}$ & 0.2732 & 0.4037 & 0.3810 & 0.3644 & 0.4146 & 0.3994 & 0.3832 & 0.3566 & 0.3603 & 0.3408 & 0.3216 & 0.3383 \\
$\mathrm{C}_{2}$ & 0.2888 & 0.2581 & 0.3112 & 0.3031 & 0.3581 & 0.3279 & 0.3136 & 0.3015 & 0.2977 & 0.2789 & 0.2492 & 0.2961 \\
$\mathrm{C}_{3}$ & 0.2249 & 0.2685 & 0.1972 & 0.2290 & 0.2627 & 0.2811 & 0.2769 & 0.2228 & 0.2411 & 0.2112 & 0.2045 & 0.2196 \\
$\mathrm{C}_{4}$ & 0.2243 & 0.2596 & 0.2301 & 0.1858 & 0.2942 & 0.2697 & 0.2363 & 0.2259 & 0.2291 & 0.2000 & 0.2011 & 0.2201 \\
$\mathrm{C}_{5}$ & 0.2191 & 0.2325 & 0.2283 & 0.2189 & 0.1948 & 0.2492 & 0.2275 & 0.2137 & 0.2137 & 0.1928 & 0.1840 & 0.2082 \\
$\mathrm{C}_{6}$ & 0.3091 & 0.3498 & 0.3315 & 0.3273 & 0.3482 & 0.2620 & 0.3278 & 0.3114 & 0.2881 & 0.2617 & 0.2495 & 0.2718 \\
$\mathrm{C}_{7}$ & 0.2516 & 0.2939 & 0.2918 & 0.2708 & 0.2901 & 0.2864 & 0.2137 & 0.2460 & 0.2717 & 0.2404 & 0.2258 & 0.2221 \\
$\mathrm{C}_{8}$ & 0.3139 & 0.3558 & 0.3341 & 0.3400 & 0.3688 & 0.3556 & 0.3370 & 0.2429 & 0.2995 & 0.2932 & 0.2831 & 0.2930 \\
$\mathrm{C}_{9}$ & 0.2660 & 0.2908 & 0.2744 & 0.2710 & 0.3053 & 0.2733 & 0.2564 & 0.2438 & 0.1948 & 0.2206 & 0.2105 & 0.2553 \\
$\mathrm{C}_{10}$ & 0.2775 & 0.3158 & 0.3162 & 0.3016 & 0.3375 & 0.3159 & 0.3159 & 0.2898 & 0.2660 & 0.1984 & 0.2293 & 0.2499 \\
$\mathrm{C}_{11}$ & 0.3427 & 0.3889 & 0.3798 & 0.3704 & 0.3995 & 0.3913 & 0.3786 & 0.3521 & 0.3629 & 0.3330 & 0.2340 & 0.3411 \\
$\mathrm{C}_{12}$ & 0.2799 & 0.3332 & 0.3230 & 0.3009 & 0.3483 & 0.3294 & 0.3188 & 0.2994 & 0.2860 & 0.2634 & 0.2580 & 0.2135 \\
\hline & & & & & & & & & & & &
\end{tabular}

Step 4: Calculate the $\mathrm{D}$ and $\mathrm{R}$ value and obtaining the causal diagram

The sum of rows and sum of columns are separately denoted as D and R to figure the causal effect. The "prominence" and "relation" were in turn calculated by D+R and D-R and the result (Table 4) were used to plot the causal and effect diagram (Figure 2)

Table 4. The $\mathrm{D}$ and $\mathrm{R}$ value and the network-relationship map

\begin{tabular}{llll}
\hline $\mathrm{D}$ & $\mathrm{R}$ & $\mathrm{D}+\mathrm{R}$ & $\mathrm{D}-\mathrm{R}$ \\
\hline 4.3369 & 3.2710 & 7.6079 & 1.0660 \\
3.5840 & 3.7505 & 7.3345 & -0.1665 \\
2.8395 & 3.5987 & 6.4382 & -0.7592 \\
2.7763 & 3.4833 & 6.2596 & -0.7070 \\
2.5827 & 3.9220 & 6.5047 & -1.3393 \\
3.6382 & 3.7411 & 7.3794 & -0.1029 \\
3.1042 & 3.5857 & 6.6899 & -0.4815 \\
3.8169 & 3.3058 & 7.1227 & 0.5110 \\
3.0623 & 3.3108 & 6.3731 & -0.2485 \\
3.4138 & 3.0345 & 6.4483 & 0.3793 \\
4.2743 & 2.8505 & 7.1248 & 1.4238 \\
3.5538 & 3.1290 & 6.6829 & 0.4248 \\
\hline
\end{tabular}

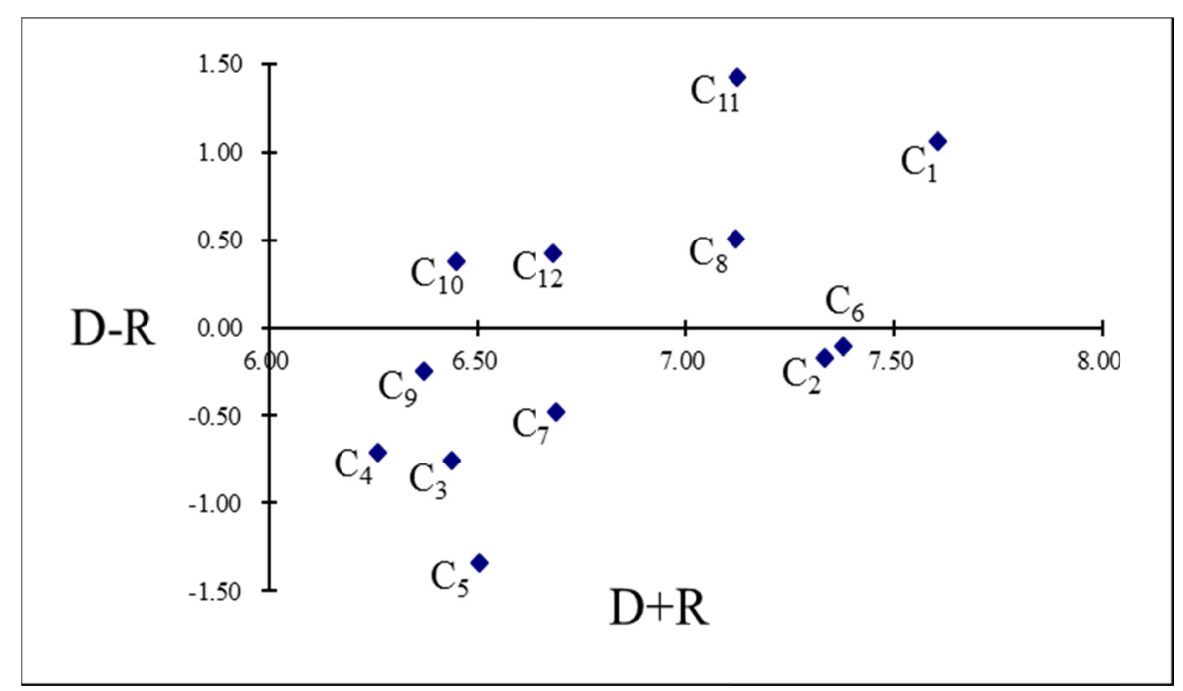

Figure 2. The cause and effect diagram 
$\mathrm{D}+\mathrm{R}$ Value

$\mathrm{D}+\mathrm{R}$ represents the importance of the key success factors. If the value is high, then that factor is considered important. In this study, the five important factors are $\mathrm{C} 1, \mathrm{C} 2, \mathrm{C} 6, \mathrm{C} 8$ and $\mathrm{C} 11$, which the values of these factors are greater than the total average value (6.8305).

D-R Value

The value D-R divides the key success factors into cause group and effect group. When the value of D-R is positive, it means that the factor is in the cause group, and if the D-R is negative, it means that the factor is in the effect group. The decision maker should analyze the values of $\mathrm{D}+\mathrm{R}$ to determine the factor that should be given highest priority, and D-R to understand which factors have an effect on each other. In this research, the causal diagram shown in Figure 1, the factors are separated into the cause group, which includes $\mathrm{C} 1, \mathrm{C} 8, \mathrm{C} 10, \mathrm{C} 11$ and C12. The effect group includes $\mathrm{C} 2, \mathrm{C} 3 \mathrm{C} 4, \mathrm{C} 5, \mathrm{C} 6, \mathrm{C} 7$ and $\mathrm{C} 9$.

The result of this research can facilitate the social practitioner to analyze and evaluate the appropriate factors in order to communicate with the target audience efficiently. Base from the finding, several implications were obtained. It would be necessary to pay attention to the cause group factors beforehand. This is because the cause group factors suggest the meanings of the influencing factors, whereas the effect group factors signify the meanings of the affected factors $(\mathrm{Wu}, 2008)$. According to the result of the total relation matrix, the evaluation factors of causal relationships among the key success factors selected from DEMATEL method can be the indicator in environmental consciousness promotion.

\section{Conclusion and Recommendation}

This research provides the social marketer to make appropriate decision in order to persuade the target audience to improve environmental consciousness. The result of total matrix and the causal diagrams signify as follow: First of all, the social practitioner needs to attain high degree performance in the effect factor. It would be suggests paying more attention to the "cause factor" previously. The components of "Take advantage of existing successful campaign", "Using appropriate media channel to increase the participation", "Maximize the promotion of the information", "Enhancing campaign success by appropriate research", and "Track the results and make adjustment" are the influencing key success factors which influence.

Secondly, the social practitioner must be applied effective strategies to capture the attention of the target audience. Base from the result, the factors "Take advantage of existing successful campaign", "Make access easy", "Start with most ready target audience intervention", "Enhancing campaign success by appropriate research", and "Using appropriate media channel to increase the participation", which these values are greater than the total average value are more important than the others.

Lastly, this research concludes that "Take advantage of existing successful campaign", "Using appropriate media channel to increase the participation", and "Enhancing campaign success by appropriate research" are generally important and belong to the cause group. The social practitioner must devote more effort to these factors before planning the social marketing strategy as for engaging the target audience to be concern about environmental protection. To make a social marketing campaign successful, these approach needs to be implementing systematically and comprehensively.

Using existing successful experience campaign is an important social marketing mix that encourages effective behavior change (Low et al., 2013). When planning the social marketing campaign, the designer may learn the successes and failures from the past experience in order to come up with an innovative and cost effective strategy. Base from the existing campaign, it is possible that the social marketer will discover the appropriate ideas or materials for creative implementation.

It is important to explore cases of prior related campaigns and what has directed to the success or failure when planning the environmental consciousness activity. There is a need for more research and guidance on better practices. According to the conclusion of Solaiman et al. (2015), customer research help to achieve the success of social campaign. The objectives of social marketing should be considered in recommending which strategies to apply, and how to research and evaluate the campaign.

Various communication channels have been applied in many social marketing interventions aimed to foster the desired behavior change, such as Evans et al. (2014) claimed that print and electronic media were useful in disseminate hygiene-related massage. Corner and Randall (2011) emphasized that advertisement through video storytelling urging individuals to response to energy efficiency social marketing. Hermsley and Dann (2014) provided a social marketing perspective on ways that facilitated communication is presented and discussed on social media platform. Key and Czaplewski (2017) also concluded that using precise channels will maximize the 
impact of social marketing campaign. Publishing magazines and books, at the same time through radio, television, and the internet, Tzu Chi foundation enhance the moral concept, environmental consciousness into daily life. Through these media, thousands of Tzu Chi environmental volunteer, regardless of age, class, background, everyone involves in the street and practice resource recycle. These are consistent with the final result of "applying appropriate media to enhance the participation of the audience".

The result also determined that successful social campaigns provide target audiences easy ways to access and convenient locations to perform the desired behavior. Effective social campaigns establish ways to monitor progress and make important adjustments to support the objectives. This effort is obviously important when there is still time to plan. As well as, social marketing campaign increase chances of success when it starts with target market most ready for action.

The author anticipates that the outcomes of the research can be beneficial for social marketer to design the best strategy through these key success factors in the case of environmental consciousness. However, Social marketing is wide domain. It can be applied in any situation in which a socially individual behavior needs to be addressed for the public (Andreasen, 2002). This research recommends that the researcher in the future may develop other systematic methods in order to measure the effectiveness of these factors in other fields, such as health promotion, public policy, community service, emergency management or many others. In addition, the future researcher may also apply Fuzzy DEMATEL or modified DEMATEL to measure the same social marketing factors to compare the result of these methodology.

\section{References}

Altuntas, S., \& Yilma, M. K. (2016). Fuzzy Dematel Method to Evaluate the Dimensions of Marketing Resources: An Application in SMEs. Journal of Business Economics and Management, 17(3), 347-364. https://doi.org/10.3846/16111699.2015.1068220

Andreasen, A. (2002). Marketing social marketing in the social change marketplace. Journal of Public Policy and Marketing, 21(1), 3-13. https://doi.org/10.1509/jppm.21.1.3.17602

Apichatibutarapong, S. (2018). Factor Affecting on Public Awareness Concerning University Environment. Proceedings, 2, 1369-1373. https://doi.org/10.3390/proceedings2221369

Aras, R. (2011). Social marketing in healthcare. Australasian Medical Journal, 4(8), 418-424. https://doi.org/10.4066/AMJ.2011.626

Barr, S., \& Prillwitz, J. (2014). A smarter choice? Exploring the behavior change agenda for environmentally sustainable mobility. Environment and Planning C: Politics and Space, 32, 1-19. https://doi.org/10.1068/c1201

Boehm, A. (2009). Applying social marketing in the developing of volunteer program. Social Marketing Quarterly, 15(3), 67-84. https://doi.org/10.1080/15245000903131376

Buyucek, N., Kubacki, K., Rundle-Thiele, S., \& Pang, B. (2016). A systematic review of stakeholder involvement in social marketing interventions. Australasian Marketing Journal, 24(1), 8-19. https://doi.org/10.1016/j.ausmj.2015.11.001

Chakraborty, S., Tiedemann, A. V., \& Teng, P. S. (2000). Climate change: potential impact on plant diseases. Environmental Pollution, 108(3), 317-326. https://doi.org/10.1016/S0269-7491(99)00210-9

Chen, J. L., Liu, H. H., \& Chuang, C. T. (2015). Strategic planning to reduce conflicts for offshore wind development in Taiwan: A social marketing perspective. Marine Pollution Bulletin, 99, 195-206. https://doi.org/10.1016/j.marpolbul.2015.07.025

Corner, A., \& Randall, A. (2011). Selling climate change? The limitations of social marketing as a strategy for climate change public engagement. Global Environment Change, 21, 1005-1014. https://doi.org/10.1016/j.gloenvcha.2011.05.002

Deniz, D. (2016). Sustainable thinking and environmental awareness through design education. Procedia Environmental Sciences, 34, 70-79. https://doi.org/10.1016/j.proenv.2016.04.008

Dietrich, T., Rundle-Thiele, S., Schuster, L., Drennan, J., Russell-Bennett, R., Leo, C., \& Conner, J. P. (2015). Differential Segmentation responses to an alcohol social marketing program. Addictive Behavior, 49, 68-77. https://doi.org/10.1016/j.addbeh.2015.05.010

DiGuiseppi, C. G., Thorenson, S. R., Clark, L., Goss, C. W., Marosits, M. J., Currie, D. W., \& Lezotte, D. C. (2014). Church-based social marketing to motivate older adults to take balance classes for fall prevention: 
Cluster randomized controlled trial. Preventive Medicine, 67, 75-81. https://doi.org/10.1016/j.ypmed.2014.07.004

Dollatabady, H., Amiri, F., \& Bidmeshk, O. (2012). Using Social Marketing Principles to Describe Local Isfahan Managers' Attitude about Using New Energy Resources. International Journal of Marketing Studies, 4(3), 160-172. https://doi.org/10.5539/ijms.v4n3p160

Eagle, L., Hamann, M., \& Low, D. R. (2016). The role of social marketing, marine turtles and sustainable tourism in reducing plastic pollution. Marine Pollution Bulletin, 107, 324-332. https://doi.org/10.1016/j.marpolbul.2016.03.040

Eagle, L., Osmond, A., McCarthy, B., Low, D., \& Lesbirel, H. (2017). Social marketing strategies for renewable energy transitions. Australasian Marketing Journal, 25, 141-148. https://doi.org/10.1016/j.ausmj.2017.04.006

Ershadi, M. J., \& Ashtiyani, F. K. (2019). Analyzing the factors affecting environmental risks of projects using a hybrid approach of DEMATEL - ANP, artificial neural network: A case study. Environmental Quality Management, 29(1), 77-88. https://doi.org/10.1002/tqem.21647

Esch, P., Esch, L. J., \& Cowley, J. C. P. (2013). The Dimensions of Religion as Underpinning Constructs for Mass Media Social Marketing Campaigns: An Emerging Concept. International Journal of Marketing Studies, 5(1), 97-106. https://doi.org/10.5539/ijms.v5n1p96

Evan, W. D., Pattanayak, S. K., Young, S., Buszin, J., Rai, S., \& Bihm, J. W. (2014). Social marketing of water and sanitation products: A systematic review of peer- reviewed literature. Social Science and Medicine, 110, 18-25. https://doi.org/10.1016/j.socscimed.2014.03.011

Forbus, R., \& Snyder, J. L. (2013). Use of comforting to enhance social marketing success: A case study. Social Marketing Quarterly, 19(2), 97-109. https://doi.org/10.1177/1524500413483455

Gandhi, S., Mangla, S. K., Kumar, P., \& Kumar, D. (2015). Evaluating factors in implementation of successful green supply chain management using DEMATEL: A case study. International Strategic Management Review, 3, 96-109. https://doi.org/10.1016/j.ism.2015.05.001

Gholami1, S., Karimiankakolaki, M., \& Ghobeyshavi, H. (2015). Developing Marketing Strategies Based on Risk Management by Using DEMATEL Technique. European Online Journal of Natural and Social Sciences, 4(1), 1527-1539. http://european-science.com/eojnss_proc/article/view/4363

Gordon, R., Waitt, G., Cooper, P., \& Butler, K. (2018). Storying energy consumption: Collective video storytelling in energy efficiency social marketing. Journal of Environment Management, 213, 1-10. https://doi.org/10.1016/j.jenvman.2018.02.046

Goyal, S., Routroy, S., \& Singhal, A. (2019). Analyzing environment sustainability enablers using fuzzy DEMATEL for an Indian steel manufacturing company. Journal of Engineering Design and Technology, 17(2), 300-329. https://doi.org/10.1108/JEDT-02-2018-0033

Ham, M., Mrčela, D., \& Horvat, M. (2016). Insights for measuring environmental awareness. Ekonomski Vjesnik/Econviews, 1, 159-176. https://hrcak.srce.hr/ojs/index.php/ekonomski-vjesnik/article/vie w/3661

Hemsley, B., \& Dann, S. (2014). Social media and social marketing in relation to facilitated communication: Harnessing the affordances of social media for knowledge translation. Evidence-Based Communication Assessment and Intervention, 8(4), 187-206. https://doi.org/10.1080/17489539.2015.1023988

Hiramatsu, A., Kurisu, K., \& Hanak, K. (2016). Environmental Consciousness in Daily Activities Measured by Negative Prompts. Sustainability, 8(1), 24-30. https://doi.org/10.3390/su8010024

Horng, J. S., Liu, C. H., Chou, S. F., \& Tsai, C. Y. (2013). Creativity as a critical criterion for future restaurant space design: Developing a novel model with DEMATEL application. International Journal of Hospitality Management, 233, 96-105. https://doi.org/10.1016/j.ijhm.2012.06.007

Iosifidi, M. (2016). Environmental awareness, consumption, and labor supply: Empirical evidence from household survey data. Ecological Economics, 129, 1-11. https://doi.org/10.1016/j.ecolecon.2016.05.007

Kataria, M., \& Larsen, K. (2009). Effects of social marketing on battery collection. Resources, Conservation and Recycling, 53, 429-433. https://doi.org/10.1016/j.resconrec.2009.03.003

Kaur, J., Sidhu, R., Awasthi, A., Chauhan, S., \& Goyal, S. (2018). A DEMATEL based approach for investigating barriers in green supply chain management in Canadian manufacturing firms. International Journal of 
Production Research, 56(1-2), 312-332. https://doi.org/10.1080/00207543.2017.1395522

Key, T. M., \& Czaplewski, A. J. (2017). Upstream social marketing strategy: An integrated marketing communications approach. Business Horizon, 60, 325-333. https://doi.org/10.1016/j.bushor.2017.01.006

Kotchena, M. J., \& Moore, M. R. (2007). Private provision of environmental public goods: Household participation in green-electricity programs. Journal of Environmental Economics and Management, 53, 116. https://doi.org/10.1016/j.jeem.2006.06.003

Kotler, P., \& Lee, N. (2008). Social marketing: Influencing behavior for good. Thousand Oaks, CA: Sage.

Kotler, P., Roberto, N., \& Lee, N. (2002). Social marketing: Improving the Quality of Life. California Sage Inc.

Krukaset, D., \& Sahachaisaeree, N. (2010). Design elements communicate on issues of the environmental conscious concept. Procedia Social and Behavioral Science, 5, 1262-1266. https://doi.org/10.1016/j.sbspro.2010.07.272

Kubacki, K., Rundle-Thiele, S., Pang, B., \& Buyucek, N. (2015). Minimizing alcohol harm: A systematic social marketing. Journal of Business Research, 68, 2214-2222. https://doi.org/10.1016/j.jbusres.2015.03.023

Kumar, A., \& Dash, M. K. (2016). Using DEMATEL to construct influential network relation map of consumer decision-making in e-marketplace. International Journal of Business Information Systems, 21(1), 48-72. https://doi.org/10.1504/IJBIS.2016.073380

Lefebvre, R. (2012). Transformative social marketing: co - creating the social marketing discipline and brand. Journal of Social Marketing, 2(2), 118-129. https://doi.org/10.1108/20426761211243955

Lin, L., \& Lv, P. (2014). The Environmental Protection Consciousness and Countermeasures. Advanced Materials Research, 962-965, 1509-1512. https://doi.org/10.4028/www.scientific.net/AMR.962-965.1509

Low, S. T., Mohammed, A. H., \& Choong, W. W. (2013). What is the optimum social marketing mix to market energy conservation behavior: An empirical study? Journal of Environment Management, 131, 196-205. https://doi.org/10.1016/j.jenvman.2013.10.001

Maibach, E. (1993). Social marketing for the environment: using information campaigns to promote environmental awareness and behavior change. Health Promotion International, 8(3), 209-224. https://doi.org/10.1093/heapro/8.3.209

McDaniel, S., \& Rylander, D. (1993). Strategic green marketing. Journal of Consumer Marketing, 10(3), 4-10. https://doi.org/10.1108/07363769310041929

Merritt, R. K., Kamin, T., Hussenoder, F., \& Huibregtsen, J. (2017). The history of social marketing in Europe: The story so far. Social Marketing Quarterly, 23(4), 291-301. https://doi.org/10.1177/1524500417732771

Mitchell, R., Schuster, L., \& Drennan, J. (2017). Understanding how gamification influences behavior in social marketing. Australasian Marketing Journal, 25, 12-19. https://doi.org/10.1016/j.ausmj.2016.12.001

Moultrie, J., Sutcliffe, L., \& Maier. A. (2015). Exploratory study of the state of environmentally conscious design in the medical device industry. Journal of Cleaner Production, 108, 363-376. https://doi.org/10.1016/j.jclepro.2015.06.014

Moultrie, J., Sutcliffe, L., \& Maier. A. (2016). A maturity grid assessment tool for environmentally conscious design in the medical device industry. Journal of Cleaner Production, 122, 252-265. https://doi.org/10.1016/j.jclepro.2015.10.108

Muhammad, M. N., \& Cavus, N. (2017). Fuzzy DEMATEL method for identifying LMS evaluation criteria. Procedia Computer Science, 120, 742-749. https://doi.org/10.1016/j.procs.2017.11.304

Nowak, G. J., Gellin, B. G., MacDonald, N. E., \& Butler, R. (2015). Addressing vaccine hesitancy: The potential value of commercial and social marketing principles and practices. Vaccine, 33, 4204-4211. https://doi.org/10.1016/j.vaccine.2015.04.039

Perez-Mujica, L., Duncan, R., \& Bossomaier, T. (2014). Using agent-based models to design social marketing campaign. Australasian Marketing Journal, 22, 36-44. https://doi.org/10.1016/j.ausmj.2013.12.006

Pettigrew, S. (2016). Pleasure: An under-utilized "p" in social marketing for healthy eating. Appetite, 104, 60-69. https://doi.org/10.1016/j.appet.2015.10.004

Reichert, T., Hecker, S. E., \& Jackson, S. (2001). The effect of sexual social marketing appeals on cognitive processing and persuasion. Journal of Advertising, 30(1), 13-27. 
https://doi.org/10.1080/00913367.2001.10673628

Sampogna, G., Bakolis, I., Evan-Lacko, S., Robinson, E., Thronicroft, G., \& Henderson, C. (2017). The impact of social marketing campaigns on reducing mental health sigma: Results from the 2009-2014 Time to Change Program. European Psychiatry, 40, 116-122. https://doi.org/10.1016/j.eurpsy.2016.08.008

Sánchez, M. J., \& Lafuente, R. (2010). Defining and measuring environmental consciousness. Revista Internacional de Sociología, 68(3), 731-755. https://doi.org/10.3989/ris.2008.11.03

Saunders, S., Barrington, D., \& Sridharan, S. (2014). Redefining social marketing: beyond behavioral change. Journal of Social Marketing, 5(2), 160-168. https://doi.org/10.1108/JSOCM-03-2014-0021

Sena, P., Royb, M., \& Pala, P. (2017). Evaluation of environmentally conscious manufacturing programs using a three-hybrid multi-criteria decision analysis method. Ecological Indicators, 73, 263-273. https://doi.org/10.1016/j.ecolind.2016.09.049

Solaiman, M., Halim, M. S., Osman, A., \& Hasen, M. (2015). Factors affecting the success of social marketing: A case of Bangladesh. International Journal of Business Technopreneurship, 5(3), 385-396. http://www.anjsbes.net.au/index. php/ANJSBES/article/view/5

Tsai, S. B., Chien, M. F., Xue, Y., Li, L., Jiang, X., Chen, Q., \& Wang, L. (2015). Using the Fuzzy DEMATEL to Determine Environmental Performance: A Case of Printed Circuit Board Industry in Taiwan. PloS One, 10(6), 1-18. https://doi.org/10.1371/journal.pone.0129153

Tzeng, G. H., Chiang, C. H., \& Li, C. W. (2007). Evaluating intertwined effects in learning programs: A novel hybrid MCDM model based on factor analysis and DEMATEL. Expert System with Application, 32, 1028 1044. https://doi.org/10.1016/j.eswa.2006.02.004

Umuhire, M. L., \& Fang, Q. (2016). Method and application of ocean environmental awareness measurement: Lessons learnt from university students of China. Marine Pollution Bulletin, 102, 289-294. https://doi.org/10.1016/j.marpolbul.2015.07.067

Uzuna, F. V., \& Kelesa, O. (2012). The effects of nature education project on the environmental awareness and behavior. Procedia - Social and Behavioral Sciences, 46, 2912-2916. https://doi.org/10.1016/j.sbspro.2012.05.588

$\mathrm{Wu}, \mathrm{W}$. W. (2008). Choosing knowledge management strategies by using a combined ANP and DEMATEL approach. Expert Systems with Applications, 35(3), 828-835. https://doi.org/10.1016/j.eswa.2007.07.025

Wu, W. W., \& Lee, Y. T. (2007). Develop global managers' competencies using the fuzzy DEMATEL method. Expert Systems with Applications, 32(2), 499-507. https://doi.org/10.1016/j.eswa.2005.12.005

Wymer, W. (2010). Rethinking the boundaries of social marketing: Activism or advertising. Journal of Business Research, 63, 99-103. https://doi.org/10.1016/j.jbusres.2009.02.003

Zhou, Q., Huang, W., \& Zhang, Y. (2011). Identifying critical success factors in emergency management using a fuzzy DEMATEL method. Safety Science, 49, 243-252. https://doi.org/10.1016/j.ssci.2010.08.005

Zhou, X., Shi, Y., Deng, X., \& Deng, Y. (2017). D-DEMATEL: A new method to identifying critical success factors in emergency management. Safety Science, 91, 93-104. https://doi.org/10.1016/j.ssci.2016.06.014

\section{Copyrights}

Copyright for this article is retained by the author, with first publication rights granted to the journal.

This is an open-access article distributed under the terms and conditions of the Creative Commons Attribution license (http://creativecommons.org/licenses/by/4.0/). 